\title{
¿Son los Estados Unidos un paraíso fiscal?
}

\author{
Are the United States a Tax Heaven? \\ Les États-Unis sont un paradis fiscal?
}

\section{David Moussali Cole*}

SUMARIO: I. Introducción. II. Los paraísos fiscales y su relación con la legislación mexicana. III. Análisis de las razones de por qué los Estados Unidos son un régimen fiscal preferente. IV. Conclusión. V. Bibliografía.

* Universidad Nacional Autónoma de México, México; ORCID ID: https: / /orcid.org/00 00-0002-2332-9277,dmoussali@gmail.com. 
Resumen: La reforma fiscal de los Estados Unidos de América, que entró en vigor en 2018, ha traído varios cambios relevantes, dentro de los cuales el más importante consiste en la disminución de la tasa del impuesto sobre la renta corporativo federal del 35\% al 21\%. Lo anterior trae como consecuencia que, conforme al artículo 176 de la Ley del Impuesto Sobre la Renta de los Estados Unidos Mexicanos, los Estados Unidos puedan ser considerados un régimen fiscal preferente. Asimismo, se analiza la posibilidad de que los Estados Unidos sean clasificados como un paraíso fiscal por su reticencia a entrar en el CRS de la OCDE y por el trato inequitativo que da a los países que colaboran con dicho país en relación con FATCA.

Palabras clave: paraísos fiscales, régimen fiscal preferente, Estados Unidos, intercambio de información, tasa del impuesto sobre la renta.

ABSTRACT: The Tax Reform of the United States of America that came into force in 2018 has brought several relevant changes, the most important of which is the reduction of the federal corporate income tax rate from $35 \%$ to $21 \%$. The foregoing results in that, according to Article 176 of the Income Tax Law of the United Mexican States, is that the United States of America may be considered a preferential tax regime. Likewise, the possibility of the United States being classified as a tax haven is analyzed due to its reluctance to enter into the OECD CRS and due to the unequal treatment it gives to the countries that collaborate with that country in relation to FATCA.

Key words: tax havens, preferential tax regime, United States, information exchange, income tax rate.

RÉSUMÉ: La réforme fiscale des États-Unis d'Amérique qui est entrée en vigueur en 2018 a apporté plusieurs changements importants, dont le plus important est la réduction du taux fédéral d'imposition des sociétés de $35 \%$ à $21 \%$. Ce qui précède a pour conséquence que, conformément à l'article 176 de la Loi de l'impôt sur le Revenu des États-Unis du Mexique, les États-Unis d'Amérique peuvent être considérés comme un régime fiscal préférentiel. De même, la possibilité que les États-Unis soient classés comme paradis fiscal est analysée en raison de leur réticence à entrer dans le CRS de l'OCDE et du traitement inégal qu'il accorde aux pays qui collaborent avec ce pays dans le cadre de la FATCA.

Mots-clés: paradis fiscal, régime fiscal préférentiel, États-Unis, échange d'informations, taux d'imposition sur le revenu. 


\section{INTRODUCCIÓN}

La reforma fiscal de los Estados Unidos de América (EUA), que entró en vigor en 2018, ha traído varios cambios relevantes, dentro de los cuales el más importante consiste en la disminución de la tasa del impuesto sobre la renta corporativo federal del 35\% al 21\%. Asimismo, respecto de la tasa aplicable a las personas físicas, ha disminuido en la tasa progresiva superior del 39.6\% al 37\%.

El cambio en la tasa corporativa del impuesto sobre la renta americano se refleja claramente conforme a lo dispuesto en la Sección 11(b) del Código de Rentas Internas de los Estados Unidos de América.

Lo anterior trae como consecuencia que, conforme al artículo 176 de la Ley del Impuesto Sobre la Renta de los Estados Unidos Mexicanos (LISR), los EUA puedan ser considerados un régimen fiscal preferente (REFIPRE), dado que dicho artículo señala lo siguiente en su tercer párrafo:

Para los efectos de esta Ley, se considerarán ingresos sujetos a regímenes fiscales preferentes, los que no estén gravados en el extranjero o lo están con un impuesto sobre la renta inferior al $75 \%$ del impuesto sobre la renta que se causaría y pagaría en México, en los términos de los Títulos II o IV de esta Ley, según corresponda. No se considerará el impuesto sobre dividendos señalado en el segundo párrafo del artículo 140 de la presente Ley al momento de determinar los ingresos sujetos a regímenes fiscales preferentes (énfasis añadido). ${ }^{1}$

Es decir, dado que la nueva tasa del impuesto sobre la renta federal de los EUA es del 21\%, esto trae como consecuencia que sea menor a la tasa del 22.5\% señalada en el artículo 176 de la LISR, ya que ésta se obtiene al multiplicar la tasa del 30\% señalada en el artículo 9o. de la LISR por el 75\%, lo que da como resultado una tasa del 22.5\%. Dado que la tasa federal americana es menor a una del 22.5\%, entonces debe ser tomada

1 Cámara de Diputados del H. Congreso de la Unión, Ley del Impuesto Sobre la Renta, véase párrafo tercero del artículo 176. Última reforma, Diario Oficial de la Federación (DOF), 9 de diciembre de 2019, disponible en: http://www.diputados.gob.mx/LeyesBiblio/pdf/ LISR_301116.pdf(fecha de consulta: 21 de agosto de 2020). 
como la tasa de una jurisdicción considerada un régimen fiscal preferente conforme a la LISR.

La controversia se da debido que nunca se había considerado la mera posibilidad de que los EUA sean un régimen fiscal preferente porque que la tasa corporativa de los EUA siempre era mayor a la de México. Asimismo, el efecto que trae el que se clasifique a un país un régimen fiscal preferente es que se considerará como si la persona moral extranjera, o figura jurídica extranjera, estuviera difiriendo el impuesto sobre la renta en México que debería pagar, por lo que se estaría obligando a dicha persona moral, o figura jurídica extranjera, a que adelante el pago del impuesto sobre la renta al final de cada ejercicio fiscal, aunque dicha persona moral o figura jurídica no haya emitido un dividendo o haya hecho cualquier tipo de distribución.

Otro efecto negativo muy importante es que si se determinara que los EUA son un régimen fiscal preferente, las tasas de retención que se le aplicarían a pagos hacia los EUA serían altísimas, puesto que podrían llegar al $40 \%$ del pago que se le haga a un residente en el extranjero. Esto conforme a lo dispuesto por el artículo 171 de la LISR, que señala que los ingresos que reciban residentes en el extranjero que estén en un régimen fiscal preferente o que sean transparentes, estarán sujetos a una retención a la tasa del 40\% sobre dichos ingresos, sin deducción alguna. El impuesto del 40\% sobre los pagos debe ser hecho por el contribuyente residente en México, que haría el pago hacia los EUA, o por el residente en el extranjero con establecimiento permanente en México.

Lo anteriormente comentado es muy delicado, ya que los EUA compran aproximadamente un $80 \%$ de las exportaciones de México, ${ }^{2}$ volviéndolo el mayor socio comercial de México, por lo que sería altamente riesgoso que México le imponga retenciones del $40 \%$ a los pagos que reciba su mayor socio comercial, lo que llevaría a medidas defensivas de los EUA hacia México. En números, podemos ver que las exportaciones de México hacia los EUA en 2018 representaron ingresos para México por la cantidad 328,059.3 millones de dólares. ${ }^{3}$ Las retenciones mencionadas serían muy relevantes, dado que del 100\% de las importaciones que llegan a México, el

2 Banco Santander, S. A., "Cifras del comercio exterior en México", véase segundo párrafo, disponible en: https: / / es.portal.santandertrade.com / analizar-mercados/mexico/cifras-comercioexterior (fecha de consulta: 21 de agosto de 2020).

3 Secretaría de Economía, Subsecretaría de Comercio Exterior, gobierno de los Estados Unidos Mexicanos, "Exportaciones totales de México", véase tabla disponible en: https: / / 
$46.4 \%{ }^{4}$ provienen de los EUA. Esto haría que casi el 50\% de los pagos al extranjero por comercio llevarían una retención del 40\%, conforme a la LISR.

Del otro lado del espejo, podemos ver que en 2018 las exportaciones de los EUA hacia México representaron un 15.9\% del total de las exportaciones realizadas por los $\mathrm{EUA}^{5}$ (México es el segundo socio comercial más importante de los EUA, después de Canadá). Dichas exportaciones le representaron, en 2018, ingresos por 265 billones de dólares. ${ }^{6}$ Si las autoridades tributarias clasificaran a los EUA como un régimen fiscal preferente, sus ingresos serían disminuidos a 159 billones de dólares, al aplicarle una retención del 40\% a los pagos que se dirigieran al país del norte en el caso de que todos los pagos se hagan a personas morales o entidades transparentes americanas.

No obstante, la regla 3.18.23 de la Resolución Miscelánea Fiscal para 2020 señala que la tasa de retención del $40 \%$ del artículo 171 de la LISR únicamente será aplicable cuando se realicen operaciones con partes relacionadas del contribuyente, conforme a la legislación de precios de transferencia contemplada en la LISR. Tal disposición continúa señalando que en los casos en los que no se realicen operaciones con partes relacionadas, se deberá efectuar la retención que proceda en los términos previstos en los artículos relativos a pagos a residentes en el extranjero delTítulo V de la LISR, y deberán cumplir con los demás requisitos que establezcan las disposiciones fiscales.

El segundo párrafo de la disposición comentada en el párrafo anterior señala que cuando los pagos se realicen a partes relacionadas residentes en un país con el que México tenga en vigor un acuerdo amplio de intercambio de información, no estarán sujetos a la retención del $40 \%$ prevista en el artículo 171 de la LISR, por lo que se deberá efectuar la retención que proceda en los términos de los demás artículos delTítuloV de la LISR y se deberá cumplir con los demás requisitos que establezcan las disposiciones fiscales.

Si se interpreta a contrario sensu la regla 3.18.23 de la Resolución Miscelánea Fiscal para 2020, se llega a la conclusión de que, en el caso de pagos realizados por un contribuyente mexicano a uno residente en un régimen

www.gob.mx/cms/uploads/attachment/file/428436/Acum-Exporta nov2018.pdf (fecha de consulta: 21 de agosto de 2020).

4 Banco Santander, S. A., cit., véase segundo párrafo.

5 Office of the United States Trade Representative, Executive Office of the President, "Mexico", véase noveno párrafo, disponible en: https://ustr.gov/countries-regions/americas/me xico (fecha de consulta: 21 de agosto de 2020).

6 Idem. 
fiscal preferente (REFIPRE), se aplicaría la tasa de retención del 40\% si el país de residencia del país considerado como REFIPRE no tiene celebrado un acuerdo amplio de intercambio de información. En el caso de EUA existe tanto un Tratado para Evitar la Doble Tributación, celebrado el 18 de septiembre de 1992 entre México y EUA, que, en su artículo 27, prevé lo relativo al intercambio de información, como un acuerdo amplio de intercambio de información celebrado con anterioridad al tratado para evitar la doble tributación, celebrado el 9 de noviembre de 1989.

Otra consecuencia que traería aparejada el apreciar a los EUA como un régimen fiscal, además de obligar a los contribuyentes al pago del impuesto sobre la renta en México por ingresos sujetos a un REFIPRE, sería que los contribuyentes mexicanos estarían forzados a cumplir con las obligaciones de reporte establecidas en el artículo 178 de la LISR, relativas a la presentación de declaraciones informativas sobre los ingresos generados en regímenes fiscales preferentes en el ejercicio inmediato anterior que tendrían que presentar en el mes de febrero posterior al ejercicio fiscal en el que hayan tenido dichas inversiones.

Por otro lado, el hecho de que EUA no haya entrado como signatario al Common Reporting Standard (CRS) de la Organización para la Cooperación y Desarrollo Económico (OCDE) escudándose en el hecho de que ha celebrado acuerdos intergubernamentales con varios países en virtud del impuesto extraterritorial americano denominado Foreign Account Tax Compliance Act (FATCA), puede hacer valorar a los EUA como un paraíso fiscal, dado que no comparte información con otros países de forma multinivel, como lo requiere el CRS, sino que sólo lo hace a un nivel, por lo que varios contribuyentes pueden tomar ventaja de esto para ocultar su identidad dentro de estructuras fiscales que podrían implementar con fideicomisos o entidades corporativas.

\section{LOS PARAÍSOS FISCALES Y SU RELACIÓN CON LA LEGISLACIÓN MEXICANA}

La introducción del régimen de paraísos fiscales en México se da en la LISR vigente en 1997. Dicha legislación creó un régimen especial de gravamen 
para los contribuyentes que inviertan capitales en Estados extranjeros clasificados como "paraísos fiscales".

La particularidad del nuevo régimen fiscal especial introducido en la LISR residía en gravar los rendimientos de inversiones en paraísos fiscales, equivalente a anticipar el impuesto sobre la renta (ISR) de los futuros dividendos a distribuirse por las sociedades o entidades residentes en dichas jurisdicciones. Es decir, mediante el nuevo régimen el fisco mexicano busca gravar ingresos que aún no han sido percibidos por los contribuyentes mexicanos porque pretende castigar las inversiones de éstos en jurisdicciones donde la tributación es nula o muy baja.

Conforme al autor Enrique Calvo Nicolau, los Estados considerados por la LISR de 1998 como jurisdicciones de baja imposición fiscal, o paraísos fiscales, son de varias clases en razón de sus sistemas tributarios:

1) Estados que no imponen impuestos a sus residentes, ya sea que sus ingresos provengan de una fuente de riqueza ubicada en el propio Estado o de fuentes ubicadas en Estados extranjeros.

2) Estados que: a) sí imponen contribuciones a sus residentes, pero a tasas muy bajas de impuesto, inferiores a las establecidas internacionalmente o a las dispuestas en México para gravar conceptos similares, o b) otorgan exenciones para los ingresos procedentes de fuentes de riqueza ubicadas en el extranjero.

3) Estados cuyo régimen jurídico dispone diversos privilegios para ciertas inversiones, como por ejemplo, exenciones por largos periodos a fin de atraer inversiones productivas que beneficien la economía del país con motivo de la generación de empleos. ${ }^{7}$

A fin de lograr mayor transparencia, en 2002 se incorporó a la LISR el término regímenes fiscales preferentes (REFIPRES), el cual estableció que los ingresos que estaban sujetos a REFIPRES no están gravados en el extranjero o lo estaban con un ISR inferior al 75\% del que se causaría en México en ese entonces; o sea, el 22.5\% para personas físicas o morales

7 Calvo Nicolau, Enrique, Tratado del impuesto sobre la renta, México, Themis, 1998, p. 1223. Los paraísos fiscales se caracterizan por tener nula o baja imposición y por otorgar privilegios a inversiones extranjeras en su jurisdicción. 
en dicho ejercicio fiscal. ${ }^{8}$ Con esta fórmula matemática se le quitaba relevancia a la lista referida, conocida en el ámbito fiscal internacional como la lista negra de la LISR, y se sustituía para efectos de determinar los impuestos efectivamente pagados en una jurisdicción menores a las tasas aludidas como ingresos sujetos a REFIPRES. Sin embargo, la lista negra permaneció relevante, y aún lo es, por la cuestión de la declaración anual informativa de REFIPRES.

Dichas reglas fueron incorporadas al Título VI de la LISR, denominado "De los regímenes fiscales preferentes y de las empresas multinacionales", en el Capítulo I, titulado "De los regímenes fiscales preferentes", y abarca de los artículos 176 a 178 de la LISR, tal y como se puede observar dentro del contenido de la LISR en vigor publicada en la página web de la Cámara de Diputados del H. Congreso de la Unión de los Estados Unidos Mexicanos. ${ }^{9}$ El Título VI de la LISR de referencia contiene las reglas relativas a la legislación antidiferimiento y a la obligación de operar a precios de mercado. ${ }^{10}$

El artículo 176 de la LISR señala que los residentes para efectos fiscales en México y los establecimientos permanentes en este país deberán pagar el impuesto conforme a ciertas reglas especiales, en relación con: a) los ingresos sujetos a REFIPRES que obtengan mediante entidades o figuras jurídicas extranjeras ${ }^{11}$ en las que participen, directa o indirectamente, y b) los ingresos que obtengan por medio de entidades o figuras jurídicas extranjeras que sean transparentes fiscales en el extranjero. ${ }^{12}$

8 Bolaños, Martha P., “Off Shore, los paraísos fiscales ¿para la evasión?”, Alto Nivel, 10 de abril de 2013, véase cuarto párrafo, disponible en: https: / /www.ccpm.org.mx/avisos/off_shore. pdf (fecha de consulta: 21 de agosto de 2020).

9 Cámara de Diputados del H. Congreso de la Unión, Ley del Impuesto Sobre la Renta, cit., véase pp. 207-226.

10 Álvarez Alcalá, Alil, Lecciones de derecho fiscal, 2da. ed., México, Oxford, 2015, p. 321. La parte de la LISR que regula los regímenes fiscales preferentes provee reglas de antidiferimeinto y de precios de transferencia.

11 Conforme al artículo 4o. A de la LISR vigente a partir del ejercicio fiscal 2020, las entidades extranjeras transparentes fiscales y las figuras jurídicas extranjeras, sin importar que la totalidad o parte de sus miembros, socios, accionistas o beneficiarios acumulen los ingresos en su país o jurisdicción de residencia, tributarán como personas morales y estarán obligadas al pago del ISR cuando sean clasificadas como residentes en México por tener en territorio nacional la administración prinicpal del negocio o su sede de dirección efectiva.

12 Álvarez Alcalá, Alil, op. cit., p. 321. 
En efecto, la LISR señala, en el artículo 176, párrafo tercero, que se considerarán ingresos sujetos a regímenes fiscales preferentes los que no están gravados en el extranjero o lo están con un impuesto sobre la renta inferior al 75\% del impuesto sobre la renta que se causaría y pagaría en México. Es decir, la tasa aludida se refiere a una tasa impositiva efectiva y no nominal, como lo señala el artículo 9o. de la LISR, que prevé que la tasa corporativa nominal en México es del 30\%. El efecto que esto trae aparejado es que la LISR dispone que para no valorar como ingresos sujetos a un régimen fiscal preferente dichos ingresos, deben tributar conforme a una tasa efectiva del $22.5 \%$; o sea, la tasa del 22.5\% debe darse en relación con el ingreso una vez que ya se hayan restado de la utilidad fiscal las deducciones correspondientes y las pérdidas fiscales de años anteriores.

Además de la definición de REFIPRES aludida, relacionada con la tasa efectiva de impuestos del $22.5 \%$ para personas morales y del $26.25 \%$ para personas físicas en la tasa progresiva más alta de la LISR, la LISR, en el párrafo primero del artículo 176, incluye una lista enunciativa de otros ingresos que se consideran que están sujetos a REFIPRES que se dan cuando se obtienen ingresos a través de entidades o figuras jurídicas extranjeras que sean transparentes fiscales en el extranjero, cuando no son consideradas como contribuyentes del ISR en el país en que están constituidas o tienen su administración principal o sede de dirección efectiva y sus ingresos son atribuidos a sus miembros, socios, accionistas, o beneficiarios.

Resulta importante señalar que, en términos generales, la LISR, en la parte relativa a REFIPRES, dispone que el ingreso o la ganancia generada de un paraíso fiscal debe ser acumulada de manera anticipada en México por los inversionistas o propietarios de las entidades residentes o ubicadas en estos territorios. ${ }^{13}$ En efecto, el ingreso obtenido de dicha entidad ubicada en un paraíso fiscal puede ser reconocido sobre una base neta (después de deducciones) si se mantiene la documentación comprobatoria en México y se cumple con requisitos de declaración de estas inversiones, o sobre una base bruta en los demás casos. ${ }^{14}$

13 Colegio de Contadores Públicos de México e Instituto Mexicano de Contadores Públicos, Introducción a los impuestos internacionales, México, IMCP, 2006, p. 237. La legislación antidiferimiento busca adelantar el pago de los impuestos que se encuentran estacionados fuera de una jurisdicción con el fin de evitar el pago de impuestos en el país de residencia fiscal.

14 Idem. 
Con la reforma fiscal 2020, aprobada el 31 de octubre de 2019 y que entró en vigor el 1o. de enero de 2020, se adicionaron varias disposiciones relacionadas con REFIPRES. Una de esas disposiciones, muy importante para nuestro estudio, fue la introducción de normas que buscan aclarar que para efectos de determinar si los ingresos de una entidad extranjera controlada se encuentran sujetos a REFIPRE, se tienen que tomar en cuenta todos los ISR pagados; es decir, tanto los impuestos federales como los locales pagados en el país de residencia o de origen y todos los impuestos retenidos en México, excepto los impuestos retenidos sobre dividendos. ${ }^{15}$

\section{ANÁLISIS DE LAS RAZONES DE POR QUÉ LOS ESTADOS UNIDOS SON UN RÉGIMEN FISCAL PREFERENTE}

\section{Reforma fiscal estadounidense 2018}

Con la reforma fiscal de los EUA aprobada por el Congreso y refrendada por el presidente el 22 de diciembre de 2017, ${ }^{16}$ pasó a ser ley la Ley Pública 115-97 (Public Law 115-97), también conocida como la Tax Cuts and Jobs Act of 2017, conocida en el ámbito fiscal como "los recortes fiscales de Trump" o la reforma fiscal estadounidense. ${ }^{17}$

La ley citada representa la reforma más importante al sistema tributario estadounidense en 30 años — desde 1986, ${ }^{18}$ para ser exactos — y trae

15 Idem.

16 Avi-Yonah, Reuven S. y Vallespinos, Martin, "The Elephant Always Forgets: US Tax Reform and the WTO”, University of Michigan Law \& Econ Research Paper, núm. 18-006; University of Michigan Public Law Research Paper, Estados Unidos, núm. 596, 28 de enero de 2018, p. 1. La Tax and Jobs Act fue aprobada por el Congreso americano y refrendada por el presidente Trump el 22 de diciembre de 2017, sin embargo, no entró en vigor hasta el 1o. de enero de 2018.

17 Knyazev, Timur, US Tax Reform for Hipsters, Estados Unidos, Timur Knyazev, CPA, 2018, p. 1. El verdadero nombre de la reforma fiscal estadounidense de 2018 es Tax and Jobs Act of 2017 porque fue aprobada en diciembre del 2017.

18 Auerbach, Alan J., "Measuring the Effects of Corporate Tax Cuts", Journal of Economic Perspectives, Estados Unidos, vol. 32, núm. 4, otoño de 2018, p. 1. La última gran reforma al sistema fiscal americano se dio con la reforma fiscal de 1986; es decir, tuvieron que pasar más de 30 años para que se diera una nueva reforma, la cual tuvo lugar hasta el 22 de diciembre de 2017. 
cambios dramáticos al, de por sí, complicado y fascinante mundo de los impuestos estadounidenses. ${ }^{19}$

El objetivo detrás de la reforma fiscal 2018 de los EUA fue hacer más competitiva a la economía norteamericana y, específicamente, se buscó incrementar la productividad corporativa en $2.5 \%$, que se traduce en un incremento del $1.2 \%$ del producto interno bruto (PIB) de los EUA después de 10 años. ${ }^{20}$

La cuestión más relevante de la reforma fiscal estadounidense fueron las reformas a la Sección 11 del Código Fiscal estadounidense de 1986 (US Internal Revenue Code), dentro de las cuales destaca la baja de la tasa del ISR en las empresas de los EUA, con lo cual la tasa gradual corporativa federal, que iba del 15\% a una máxima del 35\%, utilizada hasta el 31 de diciembre de 2017, se sustituyó por una tasa fija del 21\% a partir del 1o. de enero de 2018 .

Cabe señalar que las empresas creadas bajo las leyes de cualquiera de los 50 estados (y el Distrito de Columbia), generalmente, están sujetas al ISR corporativo de los EUA sobre sus ingresos obtenidos en todo el mundo; es decir, sobre una renta mundial. El ingreso gravable de dichas personas morales se obtiene al sumar los ingresos brutos menos las deducciones permitidas. ${ }^{21}$

Además de la reducción de la tasa corporativa del impuesto sobre la renta del 35\% al 21\%, la Tax Cuts and Jobs Act contiene características como el cambio de un sistema de renta mundial a un sistema de tributación territorial respecto de la tributación de dividendos generados en el extranjero al implementar un sistema de participation exemption, así como la deducción inmediata de ciertos activos. ${ }^{22}$ Esto llevó a que se mejorara sustancialmen-

19 Knyazev, Timur, op. cit., p. 1. La reforma fiscal estadounidense de 2018 trae la reducción de la tasa corporativa y la implementación de un régimen territorial con relación a ingresos foráneos.

20 Barro, Robert J. y Furman, Jason, "Macroeconomic Effects of the 2017 Tax Reform”, Brookings Papers on Economic Activity, Estados Unidos, vol. 2018, núm. 1, 2018, p. 257. El incremento del PIB de los EUA en 1.2\% en 10 años sería un gran logro, dado que en economías de gran desarrollo es muy díficil crear ese tipo de aumentos en el PIB porque hoy en día gozan de grandes niveles de desarrollo, por lo que no hay tanto espacio para crecimiento.

21 Véase párrafo séptimo de "Regímenes fiscales preferentes y los Estados Unidos", Contaduría Pública, mayo de 2018, disponible en: http://contaduriapublica.org.mx/2018/05/03/ regimenes-fiscales-preferentes-y-los-estados-unidos/(fecha de consulta: 21 de agosto de 2020).

22 Heinemann, Friedrich et al., "Implications of the US Tax Reform for Transatlantic FDI", Intereconomics, Alemania, vol. 53, 2018, p. 87. La reforma fiscal estadounidense trajo la re- 
te la posición global de los EUA en torno a la competencia fiscal a nivel internacional. En efecto, la reducción de la tasa estatutaria trajo a la tasa corporativa mucho más cerca de la media y el promedio de otros países de la OCDE, y ha incrementado significativamente los incentivos de inversión en capital tangible en los EUA, en relación con las tasas marginal y efectiva promedio, asumiendo un uso promedio de deuda y capital..$^{23}$ La mencionada reducción de la tasa corporativa americana representó altas ganancias para multinacionales americanas por este cambio dramático en su beneficio al incentivar la repatriación de sus capitales. ${ }^{24}$

La reforma fiscal 2018 de los EUA trajo otra grata sorpresa para las empresas americanas, dado que implementó un "participation exemption"; o sea, premia a las empresas multinacionales americanas que repatrian sus capitales pagados en forma de dividendos al no imponerles un gravamen cuando regresan a los EUA, ya que permite que sean deducibles totalmente dichas ganancias en contra de sus ingresos gravables domésticos y no les impone un gravamen en los EUA una vez que regresan, como se hacia antes de la reforma. ${ }^{25}$ Para muchas multinacionales americanas este cambio representó un cambio ansiado, deseado desde hacía más de 30 años, ya que se cambió un sistema que venía implementándose desde $1986 .{ }^{26}$ La imple-

ducción de la tasa corporativa, un sistema de tributación territorial y la deducción inmediata de ciertos activos.

23 Lyon, Andrew B. y McBride, William A., Assessing US Global Tax Competitiveness after Tax Reform, Estados Unidos, Pricewaterhouse Coopers LLP, National Tax Association, 9 de mayo de 2018, p. 1. La tasa corporativa estatutuaria implementada en los EUA a partir del 2018 del $21 \%$ es menor al promedio de los estados que conforman la OCDE, que tienen una tasa promedio del 23.7\%, esto le da una amplia ventaja competitiva a los EUA.

${ }^{24}$ Wagner, Alexander F. et al., "Unequal Rewards to Firms: Stock Market Responses to the Trump Election and the 2017 Corporate Tax Reform”, AEA Papers and Proceedings, Estados Unidos, 108: 590-96, 2018, p. 590. La disminunción de la tasa corporativa del 35\% al 21\% fue notoria, por lo que incentivó inversiones en los EUA por parte de las compañías que tenían dinero en el extranjero y les daba la ventaja de tributar a sólo el 15.5\% sus ganancias en efectivo que aún no habían estado sujetas a imposición previamente.

25 Donohoe, Michael P. et al., "Back to the Drawing Board: The Structural and Accounting Consequences of a Switch to a Territorial Tax System”, National Tax Journal, Estados Unidos, vol. 66 , núm. 3, 2014, p. 19. Se hablaba inicialmente de una exención del 95\% de la tributación de ganancias repatriadas a los EUA, pero en la ley actual se optó por una exención total, ya que los EUA se volvió un sistema territorial en este aspecto.

26 Herzfeld, Mindy, “US Tax Reform: Worth Waiting 30 Years For?”, láminas de presentación, Estados Unidos, University of Florida College of Law, 30 de mayo de 2018, p. 34. Desde 
mentación del "participation exemption" de la Tax Cuts and Jobs Act tenía el claro objetivo de eliminar distorsiones en la cantidad y el momento de la repatriación de dividendos.

\section{Impuestos sobre la renta previstos en el Tratado para Evitar} la Doble Tributación celebrado entre México y los Estados Unidos

Conforme al artículo 2o. del Convenio entre el Gobierno de los Estados Unidos Mexicanos y el Gobierno de los Estados Unidos de América para Evitar la Doble Imposición e Impedir la Evasión Fiscal en Materia de Impuesto Sobre la Renta, celebrado el 18 de septiembre de 1992 (el Tratado para Evitar la Doble Tributación entre México y los Estados Unidos), que sigue estando en vigor, se establece que los impuestos comprendidos en el tratado son los impuestos sobre la renta exigibles en los Estados que forman parte del tratado.

El segundo párrafo del tratado en mención señala que se consideran impuestos sobre la renta los que gravan la totalidad de la renta o cualquier parte de la misma, incluidos los impuestos sobre las ganancias derivadas de la enajenación de bienes muebles o inmuebles. De hecho, en la mayoría de los tratados de doble tributación se habla de evitar la doble tributación sobre impuestos sobre la renta a nivel federal. ${ }^{27}$

La parte relevante para nuestro estudio se menciona en el tercer párrafo del artículo 2o. del Tratado para Evitar la Doble Tributación entre México y los Estados Unidos: sólo contempla los impuestos sobre la renta federales en cada jurisdicción; es decir, el ISR previsto en la LISR vigente en México y en el Código de Rentas Internas de los Estados Unidos (el Income Tax previsto en el Internal Revenue Code).

Tomando en consideración lo señalado en el párrafo anterior, y conforme al principio de aplicación estricta de las normas tributarias contenido

1986 no había habido un cambio sustancial en el sistema impositivo americano hasta que se dio la reforma fiscal americana de 2018.

27 Avi-Yonah, Reuven S., Double Tax Treaties: An Introduction, Estados Unidos, University of Michigan Law School, SSRN, 2007, p. 6. Resulta poco ortodoxa la interpretación que el SAT dio sobre los REFIPRES por la reforma fiscal americana de 2018, ya que los tratados para evitar la doble tributación siempre versan sobre impuestos federales y no mencionan a los impuestos estatales o municipales. 
en el artículo 5o. del Código Fiscal de la Federación (CFF) de México, para efectos prácticos México sólo reconoce el ISR federal de los EUA previsto en el Código de Rentas Internas de dicho país.

A su vez, el cuarto párrafo del artículo 2o. del tratado de mérito dispone que el convenio se aplicará igualmente a los impuestos de naturaleza idéntica o análoga que se establezcan con posterioridad a la fecha de la firma del tratado y se añadan a los actuales o los sustituyan.

Por otro lado, debemos tomar en consideración lo previsto en el párrafo sexto del artículo 25 del Tratado para Evitar la Doble Tributación entre México y Estados Unidos, que regula lo relativo a la no discriminación y que podría abrir la puerta a que exista la posibilidad de incorporar el efecto de tasas utilizadas por los diferentes estados de los EUA respecto del ISR estatal para las personas morales residentes en ese país. Entonces, con el fin de que no haya discriminación en contra de una empresa residente en los EUA, el sexto párrafo del artículo 25 del tratado antes citado podría dar la posibilidad de que se sume la tasa del ISR federal del 21\% con los impuestos sobre la renta estatales de cada estado de los EUA, o incluso los locales.

Sin embargo, se debe tomar en consideración que en México no existen impuestos sobre la renta a nivel estatal ni municipal, por lo que podría pensarse injusto e inequitativo que se contemplen las tasas de los impuestos sobre la renta a nivel estatal y municipal de los EUA para hacer el cálculo para determinar la tasa del $22.5 \%$ que clasificaría a los ingresos de una empresa como ingresos de un REFIPRE. Por lo anterior, se podría aseverar que no habría discriminación conforme al tratado tributario entre México y los EUA, dado que al tomar en consideración sólo los impuestos federales entre ambos países, existiría una situación de equidad entre los países contratantes del convenio fiscal.

No obstante lo anterior, resulta preciso mencionar que aunque no existe un ISR estatal en México, hay un impuesto cedular previsto en el artículo 127 de la LISR, que estipula que los contribuyentes que enajenen terrenos, construcciones o terrenos y construcciones deben efectuar un pago por cada operación aplicando una tasa del 5\% sobre la ganancia obtenida, el cual se debe enterar mediante declaración ante la autoridad hacendaria estatal en dónde se ubique el inmueble.

Por otro lado, es importante tomar en consideración que el Código de Rentas Internas de los Estados Unidos de América permite la posibilidad 
de que el ISR estatal se deduzca de la base gravable del impuesto federal conforme a la Sección 164(a) de dicho Código. Es decir, el ISR estatal puede restarse del federal, y de esta manera se neutraliza el impuesto estatal, ya que se evita una doble o triple imposición dentro de los EUA. Sin embargo, esto nos llevaría a la conclusión de que, en realidad, el impuesto estatal no existe y afecta de manera negativa en el cálculo de la tasa del 22.5\% prevista en el artículo 176 de la LISR.

De la Sección 164(a) del Código de Rentas Internas de los Estados Unidos se puede observar claramente que es posible deducir del ISR federal de los EUA los impuestos sobre la renta estatales y locales (municipales, para efectos fiscales mexicanos), por lo que en vez de añadirse para superar la tasa del ISR para determinar la existencia de un REFIPRE, en realidad pueden disminuir la tasa corporativa efectiva de las empresas estadounidenses. Esto llevaría a que la tasa efectiva del ISR de las personas morales estadounidenses sea menor a la tasa corporativa federal del 21\%, ya que a ésta se le deducirían las tasas de los impuestos sobre la renta a nivel estatal y municipal.

Como se comentó anteriormente, en los EUA se establece que los impuestos estatales y municipales son deducibles, como los impuestos estatales y municipales sobre el ingreso, los impuestos generales estatales y locales sobre las ventas, los impuestos estatales y locales sobre los bienes raíces y los impuestos estatales y locales sobre la propiedad personal. ${ }^{28}$ Así, los impuestos estatales pueden ser deducidos del ISR federal, considerando algunas limitantes. Para ser deducibles, dichos impuestos tuvieron que haber sido pagados durante el ejercicio fiscal y reportarse como deducción detallada en los formularios que se presentan en los EUA ante el Servicio de Rentas Internas.

Lo anterior implica que si bien la tasa del ISR federal en los EUA disminuyó, lógicamente no implica la eliminación de los impuestos estatales y municipales, los cuales, como hasta antes de la entrada en vigor de la reforma fiscal, tenían, igualmente, que ser adicionados a la tasa corporativa; o sea, que la suma del ISR federal, disminuido al $21 \%$ a partir de enero de

28 Rodríguez Medina, Gilberto, Comentarios sobre la disminución de la tasa del ISR corporativo de la reforma fiscal en Estados Unidos, México, Colegio de Contadores Públicos de México, 2018, PAF 701, p. 41, Los impuestos estatales y municipales sobre la renta son deducibles en contra del ISR federal. 
2018, más el ISR estatal, podrían resultar en tasas similares a la pagada en México del 30\% vigente, o incluso superiores. ${ }^{29}$

No obstante, es importante mencionar que la reforma fiscal americana de 2018 pone una limitante a las personas físicas de una deducción de 10,000.00 de impuestos sobre la renta estatales y municipales. Dicha limitante aplica también de manera combinada con impuestos sobre la propiedad estatales y municipales. ${ }^{30}$

\section{Impuestos sobre la renta estatales}

y municipales de los Estados Unidos

En relación con lo comentado sobre la tasa corporativa de los EUA, se puede tomar en consideración que en ese país existen impuestos sobre la renta a nivel federal y a nivel estatal, por lo que se puede decir que se podrían sumar ambas tasas para evitar caer en el supuesto de REFIPRE. Se debe tomar en consideración que la tasa estatutaria federal/estatal en los EUA hasta el 31 de diciembre de 2017 era del 38.9\%, ${ }^{31}$ tasa que era mucho más alta que la del $22.5 \%$ que determina si una persona moral era considerada como REFIPRE o como paraíso fiscal, que era el concepto legal que se utilizaba anteriormente. Por otro lado, a partir del 1o. de enero de 2018, cuando entró en vigor la reforma fiscal estadounidense, la tasa estatutaria combinada federal/estatal en los EUA es, en promedio, del $25.75 \% .^{32}$

Para determinar si las entidades extranjeras controladas por contribuyentes mexicanos se encuentran sujetas a REFIPRES, debemos observar las tasas del ISR estatal en cada estado de los EUA. Las diversas tasas vigentes para el ejercicio fiscal 2019 se muestran en el siguiente diagrama:

29 Idem.

30 Internal Revenue Service, "With new SALT limit, IRS Explains Tax Treatment of State and Local Tax Refunds”, IR-2019-59, 29 de marzo de 2018, véase párrafo sexto, disponible en: https: / / www.irs.gov/newsroom/with-new-salt-limit-irs-explains-tax-treatment-of-state-andlocal-tax-refunds (fecha de consulta: 21 de agosto de 2020).

31 Gutiérrez, Mario Alberto y Chávez, Juan José, "Reforma Fiscal de los Estados Unidos y sus Efectos en México”, Cámara Española de Comercio y PwC, febrero de 2018, véase ter cera lámina, disponible en: https: / / camescom.com.mx/wp-content/uploads/2018/02/ReformaFiscal-USA-27-feb-2018_.pdf (fecha de consulta: 21 de agosto de 2020).

32 Idem. 


\section{Top Marginal Corporate Income Tax Rates as of January 1, 2019}

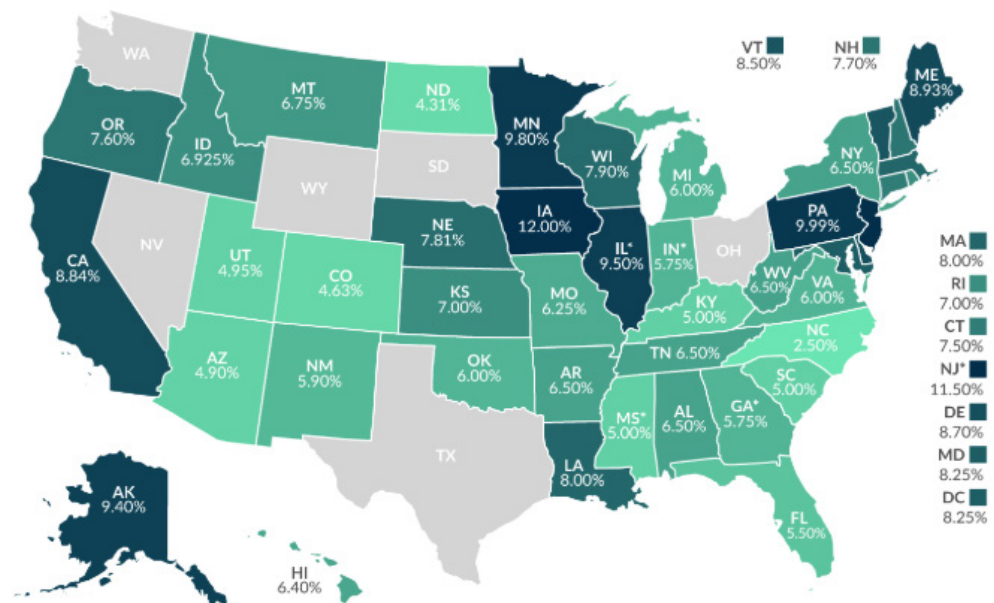

Noter (") Nevada, Ohio, Tecas, and Washington do not have a corporate income tax but do have a gross receipts tax with rates not strictly comparable to corporate income tax rates. Delaware has gross receipts taxes in addition to corporate income taxes, as do several states like Pennsyvania Virginia, and West Virginia, vithich permit gross roceipts taxes at the

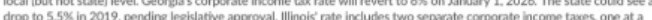
drop to $5.5 \%$ in 2019 , pendires ee 4.966 by 2022 lowa's rate is schedvied to drop to 9 a percent by 2021, subicct to reverue availability Mississippi continues to phase out the 3 percent bracket by increasing the exemption by $\$ 1,000$ a year. By the start of 2022 , the 3 percent bracket will be fully eliminated. Potential reform in 2020 will subject nearly all Missour companies to a singele sales factor appointment, permitting a rate reduction from $6.25 \%$ to 4 . In New Jersey, the rates indicated apply to a

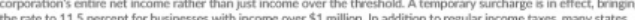
impose other tares on corporations such as gross recripts taxes and fanctive twes Some states ako impose an impose other taxes on corporations such as gross receipts taxes and

FUENTE: https: / / taxfoundation.org/state-corporate-rates-brackets-2019/.

Se debe hacer hincapié en el hecho de que no todos los estados de EUA tienen impuestos sobre la renta estatales, ${ }^{33}$ por lo que de facto dichas jurisdicciones entrarían al supuesto de REFIPRE, situación que se da con los estados de Nevada, Ohio, South Dakota, Texas, Washington y Wyoming. Por lo dicho, de entrada las empresas mexicanas que tengan entidades extranjeras controladas en dichos estados deberán reportar los ingresos que éstas generen como ingresos sujetos a REFIPRES, puesto que su tasa corporativa estatuaria será del $21 \%$, dado que tal tasa corresponde al ISR federal en los EUA y no existirá ninguna forma de añadirle otra tasa de ISR estatal.

33 Nechyba, Thomas J., "Local Property and State Income Taxes: The Role of Interjurisdictional Competition and Collusion”, Journal of Political Economy, Estados Unidos, vol. 105, núm. 2, abril de 1997, p. 1. Existe competencia fiscal en los EUA ya que no todos los estados de la Unión Americana tienen impuestos sobre la renta estatales. 
Por otro lado, conforme a los impuestos estatales si se suma la tasa estatutaria federal y estatal, los siguientes estados no llegarían a superar el 22.5\% que señala el artículo 176 de la LISR: Arkansas (cuando sea aplicable la tasa del 1\%) y North Dakota (cuando sea aplicable la tasa del 1.41\%). ${ }^{34}$

Finalmente, para nuestro estudio es importante resaltar que en los EUA también existen, en algunos estados, impuestos sobre la renta a nivel municipal; no obstante, para efectos de nuestro análisis, no son tan relevantes por sus pequeñas tasas. Sin embargo, el contemplarlos puede traer consecuencias muy positivas para evitar que se señalen como ingresos de regímenes fiscales preferentes los ingresos de empresas americanas, como es el caso del estado de Ohio, que, al no tener impuesto a nivel estatal pero sí una tasa corporativa a nivel municipal de $1.56 \%$ y sumarla a la tasa corporativa a nivel federal del $21 \%$, se saldría del supuesto de RERIPRE, ya que superaría la tasa del $22.5 \%$ por un margen muy pequeño: .06\%.

\section{Reforma fiscal mexicana 2020}

Con la aprobación de las reformas a la LISR mediante el Dictamen del Proyecto de Decreto por el que se Reforman, Adicionan y Derogan Diversas Disposiciones de la Ley del Impuesto Sobre la Renta, de la Ley del Impuesto al Valor Agregado, de la Ley del Impuesto Especial Sobre Producción y Servicios y del Código Fiscal de la Federación emitido por la Comisión de Hacienda y Crédito Público de la Cámara de Diputados, publicado en la Gaceta Parlamentaria de la Cámara de Diputados el 30 de octubre de $2019,{ }^{35}$ se buscó darle una solución a la problemática planteada por nuestro estudio. Las reformas contenidas en el dictamen fueron las que entraron en vigor el 1o. de enero de 2020.

Dentro del artículo 176 de la LISR se mantuvo el lenguaje original de la LISR vigente en 2019, que contiene la fórmula para determinar qué ingresos se consideran sujetos a REFIPRES dentro del párrafo tercero

34 Walczak, Jared, 2020 State Business Tax Climate, Tax Foundation, véase tabla disponible en: https: //taxfoundation.org/2020-state-business-tax-climate-index/ (fecha de consulta: 21 de agosto de 2020).

35 Cámara de Diputados del H. Congreso de la Unión, Gaceta Parlamentaria, año XXII, núm. 5398, 30 de octubre de 2019, véase Anexo VI, disponible en: http: / /gaceta.diputados. gob. $\mathrm{mx} /$ Gaceta/64/2019/oct/20191030.html (fecha de consulta: 21 de agosto de 2020). 
del artículo en mención, el cual citaremos nuevamente para efectos de nuestro estudio:

Para los efectos de esta Ley, se considerarán ingresos sujetos a regímenes fiscales preferentes, los que no están gravados en el extranjero o lo están con un impuesto sobre la renta inferior al 75\% del impuesto sobre la renta que se causaría y pagaría en México, en los términos de los Títulos II o IV de esta Ley, según corresponda.

La redacción citada reitera la fórmula que hemos estado manejando en el presente estudio, que determina la tasa corporativa del 22.5\% para evitar que un ingreso sea determinado como sujeto a un REFIPRE; esto porque que el 75\% de la tasa del 30\%, prevista en el artículo 9o. de la LISR, da ese resultado.

Por otra parte, se incorpora un nuevo sexto párrafo al artículo 176 de la LISR, que a letra señala:

Para realizar la determinación señalada en los párrafos anteriores, se considerarán todos los impuestos sobre la renta pagados por la entidad extranjera, sin importar que los mismos se paguen en un país o jurisdicción distintos al de su residencia o a diferentes niveles de gobierno. No se considera que un impuesto fue pagado, entre otros, cuando el mismo se realizó mediante el acreditamiento de impuestos sobre la renta o estímulos fiscales.

De la transcripción anterior vemos que en la LISR vigente en 2020, para la determinación de la existencia de ingresos sujetos a REFIPRE se pueden tomar en consideración los impuestos sobre la renta pagados en diferentes niveles de gobierno y no sólo a nivel federal.

Resulta de gran relevancia transcribir el párrafo octavo del artículo 176 de la LISR vigente a partir del 1o. de enero de 2020, que incorpora la posibilidad de hacer un comparativo de tasas estatutarias para superar la barrera de la tasa del 22.5\% prevista para sopesar a un ingreso como sujeto a un REFIPRE. Dicho párrafo señala lo siguiente:

En lugar de comparar el impuesto pagado por la entidad extranjera frente al impuesto que se causaría y pagaría en México de conformidad con los párrafos anteriores, el contribuyente podrá comparar la tasa estatutaria del impuesto sobre la renta del país o jurisdicción de su 
residencia fiscal, con la tasa establecida en el artículo 9o. de esta Ley o la tasa máxima para aplicarse sobre el excedente del límite inferior que establece la tarifa contenida en el artículo 152 de la misma, según corresponda. En estos casos, no se considerarán ingresos sujetos a regímenes fiscales preferentes cuando dichas utilidades estén gravadas con una tasa igual o mayor al 75\% de las tasas mencionadas anteriormente, siempre que sean gravables todos sus ingresos, salvo los dividendos percibidos entre entidades que sean residentes del mismo país o jurisdicción, y que sus deducciones sean o hayan sido realmente erogadas, a condición que se acumulen o deduzcan, respectivamente, en los mismos momentos señalados en los títulos II o IV de esta Ley, según corresponda. Lo señalado en este párrafo sólo será aplicable si la entidad extranjera no está sujeta a algún crédito o beneficio fiscal en su país o jurisdicción de residencia que reduzca su base imponible o impuesto a pagar que no se otorgaría en México, y cuando dicho país o jurisdicción tenga un acuerdo amplio de intercambio de información con México. Lo señalado en este párrafo no será aplicable cuando la entidad extranjera esté sujeta a diversas tasas estatuarias en su país o jurisdicción de residencia. Para estos efectos, se presume, salvo prueba en contrario, que no se reúnen los elementos previstos en este párrafo (énfasis añadido).

Finalmente, en torno a lo relacionado con la reforma fiscal 2020 en materia de REFIPRES, se observa que en las adiciones a la fórmula para determinar la existencia de un REFIPRE, consistentes en la suma de tasas estatutarias, se le pone un candado a la cláusula habilitante al señalar que la suma de tasas estatutarias no aplicará en el caso de que la entidad extranjera esté sujeta a un crédito o beneficio fiscal en su país o jurisdicción de residencia, como bien puede ser un crédito que permitiría que el impuesto pagado conforme a la tasa del ISR estatal se pueda aplicar en contra del ISR federal. Situación, que como se ha abordado en nuestro estudio, se actualiza, aunque a la fecha las autoridades tributarias han adoptado la posición de sólo analizar la suma de tasas estatutarias para superar la barrera de la tasa del 22.5\%.

\section{El intercambio de información para determinar}

si los Estados Unidos son un régimen fiscal preferente

Al observar la lista de jurisdicciones que han implementado el intercambio de información conforme al Estándar Común de Reporte de Informa- 
ción de la OCDE (mejor conocido como Common Reporting Standard o CRS), publicado en enero 2020, se observa que la mayoría de los países desarrollados del mundo han implementado el nuevo estándar de intercambio automático de información para efectos fiscales. ${ }^{36}$

Sin embargo, es importante señalar que dentro del listado, que contiene a países como Francia, Alemania, Reino Unido, España, México, etcétera, no aparecen los EUA como una jurisdicción participante. Esto es así porque los EUA se han negado a participar bajo el nuevo estándar de intercambio automático de información global para efectos fiscales. ${ }^{37}$ La justificación de su negativa para participar en el CRS es que dicho país señala que realiza su intercambio automático de información con relación la FATCA (Foreign Account Tax Compliance Act o Ley de Cumplimiento Fiscal de Cuentas Extranjeras), que es una ley extraterritorial de los EUA que amenaza a otras jurisdicciones con aplicarles una retención del 30\% en caso de que los otros países no entren a acuerdos intergubernamentales con los EUA. Dichos convenios fueron desarrollados desde el 2015 bajo los acuerdos intergubernamentales, denominados IGAs, con otras jurisdicciones. ${ }^{38}$

Conforme a la primera nota del documento de la OCDE, que comenta el estatus actual de los arreglos de intercambio automático de información de la OCDE, se señala que los EUA desarrollaron los acuerdos intergubernamentales modelo $1 \mathrm{~A}$, celebrados entre EUA y otras jurisdicciones, y reconocen la necesidad de que los EUA logre niveles equivalentes de intercambio automático recíproco de información con las demás jurisdicciones contratantes. ${ }^{39} \mathrm{~A}$ su vez, se menciona que los IGAs también incluyen

36 Global Forum on Transparency and Exchange of Information for Tax Matters, OECD, "Automatic Exchange of Information (AEOI): Status of Commitments", agosto de 2020, véase tabla disponible en: https://www.oecd.org/tax/automatic-exchange/commitment-and-monitor ing-process/AEOI-commitments.pdf (fecha de consulta: 21 de agosto de 2020).

37 Meinzer, Markus, “Automatic Exchange of Information as the New Global Standard: The End of (Offshore Tax Evasion) History”, Tax Justice Network, Reino Unido, 27 de febrero de 2017, p. 1. EUA no cumple con el nuevo estándar de intercambio automático de información internacional desarrollado por la OCDE.

38 Hakelber, Lukas, “The Power Politics of International Tax Cooperation: Luxembourg, Austria and the Automatic Exchange of Information”, Journal of European Public Policy, Reino Unido, vol. 22, núm. 3, 2015, p. 1. EUA obtiene el intercambio automático de información financiera con otras jurisdicciones a través de acuerdos intergubernamentales que celebra con otros gobiernos.

39 Idem. 
un pacto político que pretende la adopción de regulaciones y que buscan y apoyan la adopción de una legislación relevante para lograr dichos niveles equivalentes de intercambio de información recíproco.

En adición a lo anterior, es importante recordar que las autoridades tributarias de México y los EUA intercambian información por conducto del artículo 27 del Tratado para Evitar la Doble Tributación celebrado entre ambos países. Sin embargo, como se comentó, la información financiera de sus residentes fiscales se intercambia de una manera automática entre los dos Estados por conducto del IGA celebrado entre ellos.

Regresando a la materia del presente apartado, debemos recordar que el Reporte Final de la Acción 5 del Proyecto BEPS (Combatir la Prácticas Fiscales Perniciosas, teniendo en cuenta la Transparencia y la Sustancia) enuncia factores para identificar a paraísos fiscales y REFIPRES. Dentro de los factores que enuncia la OCDE para identificar a un paraíso fiscal están la leyes o prácticas administrativas que evitan el intercambio efectivo de información relevante con otros gobiernos sobre contribuyentes que se benefician de jurisdicciones con bajas o nulas tasas de imposición. ${ }^{40}$ Asimismo, la OCDE señala que las jurisdicciones que son paraísos fiscales no permiten a sus administraciones el acceso a información bancaria, lo que es crucial para detectar y prevenir la evasión fiscal. Entonces, al no disponer de la información de los contribuyentes por parte de las autoridades tributarias, se da como resultado la falta de intercambio efectivo de información, que es uno de los factores determinantes para identificar un paraíso fiscal, debido a que eso limita el acceso de las autoridades tributarias a la información requerida para la aplicación correcta y a tiempo de las leyes tributarias. ${ }^{41}$

Lo comentado se enfatiza en el reporte al señalarse que la falta del intercambio efectivo de información con relación a contribuyentes que se

40 OCDE, “Combatir las prácticas fiscales perniciosas, teniendo en cuenta la transparencia y la sustancia, Acción 5-Informe final 2015”, 2015, véase punto 15, p. 22, disponible en: https: / / www.oecd-ilibrary.org/docserver / 9789264241190-en.pdf?expires=1598038726\&id=id\&a ccname $=$ guest\&checksum $=5$ C89AF3EB302C7E25F17FBD4D2D61D74 (fecha de consulta: 21 de agosto de 2020).

41 OCDE, "Harmful Tax Practices, an Emerging Global Issue", 1998, véase punto 65, p. 30, disponible en: https://www.oecd.org/tax/harmful/1904176.pdf (fecha de consulta: 21 de agosto de 2020). 
benefician de la operación de un régimen fiscal preferencial es un indicador fuerte de que un país está involucrado en competición fiscal nociva. ${ }^{42}$

El Reporte Final de la Acción 5 del Proyecto BEPS claramente señala que la habilidad o la disposición de un país de proveer información a otros países es un factor determinante a decidir en cuanto a determinar si un régimen operado por una jurisdicción tiene el potencial para tener efectos fiscales nocivos. En el caso de los EUA no hay cuestiones de secrecía bancaria que imposibiliten el intercambio de información como las que existían en el pasado en Suiza, sino que en la actualidad existen políticas y prácticas que impiden el intercambio de información de manera efectiva con otros países, encuadrándose así un factor determinante para señalar la existencia de un paraíso fiscal. Dicha inhabilidad, o falta de disposición de la jurisdicción en intercambiar información de una manera efectiva, hace que no se pueda notificar a una autoridad tributaria extranjera información que para ésta es necesaria para poder darle más poder y así hacer efectivas sus facultades de comprobación para corregir la situación fiscal de los contribuyentes que se encuentran bajo su jurisdicción.

Los EUA no tienen un régimen de secreto bancario formalmente para residentes fiscales extranjeros; sin embargo, los proveen un secreto bancario de facto a residentes fiscales extranjeros que tienen activos en el país. Esto es porque el secreto bancario de facto se da cuando el país de fuente de riqueza, en este caso los EUA, no tiene la información relevante para el intercambio de información o no quiere compartirla con sus cosignatarios de tratados tributarios. ${ }^{43}$ El régimen de secreto bancario de facto de los EUA permite a cualquier residente fiscal extranjero el hacer depósitos en bancos norteamericanos sin revelar los ingresos obtenidos sobre esos depósitos al país de residencia del residente extranjero, ${ }^{44}$ a menos de que caiga en alguno de los supuestos previstos de información intercambiable en caso de que los EUA tengan un acuerdo intergubernamental (IGA) con el país de residencia del contribuyente. La razón detrás de esto es que el

42 OCDE, “Combatir las prácticas fiscales perniciosas...", cit., véase punto 18, p. 23.

43 Wang, Emily, "The Opaque Future of Tax Information Sharing between the United States and China: An Analysis of Bank Secrecy Laws and the Likelihood of Entrance into a Tax Information Exchange Agreement”, Hastings International \& Comparative Law Review, Estados Unidos, vol. 35, núm. 411, 2012, pp. 417 y 418. Los EUA tienen un secreto bancario de facto al no intercambiar información sobre cuentas bancarias.

44 Ibidem, p. 418. 
Congreso estadounidense permite el secreto bancario de facto porque su sistema financiero necesita capital. ${ }^{45}$

Con base en lo anterior, es importante reconocer que existe una discusión académica mundial alrededor de la definición de los paraísos fiscales, pero se debe tomar en cuenta que un país puede exhibir la conducta de un paraíso fiscal aunque tenga altas tasas impositivas en relación con su ISR. ${ }^{46}$ Este resultado se da porque muchos países de la OCDE sirven como un tipo de paraíso fiscal debido a que no revelan la información fiscal o financiera sobre sus inversionistas no residentes fiscales, lo que alienta a que persista la evasión fiscal offshore y otros crímenes financieros internacionales. ${ }^{47}$ Por ejemplo, las tres economías más grandes de la OCDE (EUA, Alemania y Japón) están listadas dentro de los 10 países con las más rígidas leyes de secrecía financiera, mientras que países que, en muchos casos, son etiquetados como paraísos fiscales (Barbados, las Bahamas y Liechtenstein) tienen clasificaciones más favorables. ${ }^{48}$

Al observar el contenido del IGA celebrado entre México y los EUA para el intercambio automático de información sobre cuentas financieras, oficialmente conocido como el Acuerdo entre la Secretaría de Hacienda y Crédito Público de los Estados Unidos Mexicanos y el Departamento del Tesoro de los Estados Unidos de América para Mejorar el Cumplimiento Fiscal Internacional, incluyendo la FATCA, se observa que claramente dicho acuerdo es inequitativo y que los EUA no está cumpliendo con sus obligaciones de intercambio automático de información conforme al nuevo estándar internacional de la OCDE. Resulta relevante destacar que el IGA México-EUA puede ser observado en el anexo 25 de la Resolución Miscelánea Fiscal para 2020.

Lo anterior es así dado que México comparte información de manera automática con los EUA de una forma multinivel, mientras que los EUA sólo comparte información con México a un nivel. Es decir, México le pasa toda la información relevante a los EUA para combatir la evasión fiscal y los EUA nada más proporcionan parte de la información relevante a México,

45 Ibidem, p. 423.

46 Cockfield, Arthur J., "Big Data and Tax Haven Secrecy”, Florida Tax Review, Estados Unidos, vol. 18, 2016, p. 6. Un país puede exhibir la conducta de un paraíso fiscal aun teniendo una alta tasa impositiva.

47 Idem.

48 Idem. 
que podría utilizar para combatir la evasión fiscal de sus contribuyentes que tienen cuentas bancarias o financieras en los EUA.

La conclusión a la que se llega se obtiene al encontrar los contrastes entre lo que significa una "cuenta reportable" para cada una de las jurisdicciones. El IGA celebrado entre México y los EUA señala lo siguiente en relación con cuentas reportables:

a) La expresión "Cuenta Reportable" significa una Cuenta Reportable a EE.UU. o Cuenta Reportable a México, según lo requiera el contexto.

b) La expresión "Cuenta Reportable a México" significa una Cuenta Financiera mantenida en una Institución Financiera de EE.UU. sujeta a reportar cuando: (i) en el caso de una Cuenta de Depósito, dicha cuenta es mantenida por una persona física residente en México y más de diez (\$10) dólares en intereses son pagados a dicha cuenta en cualquier año calendario; o (ii) en el caso de una Cuenta Financiera distinta de una Cuenta de Depósito, el Cuentahabiente sea un residente en México, incluyendo una Entidad que certifique que es residente en México para efectos fiscales, respecto de los ingresos pagados o acreditados, cuya fuente de riqueza se encuentre en EE.UU., que estén sujetos a ser reportados de conformidad con el capítulo 3 del subtítulo A o capítulo 6 del subtítulo F del Código de Rentas Internas de EE.UU.

c) La expresión “Cuenta Reportable a EE.UU.” significa una Cuenta Financiera mantenida en una institución Financiera de México Sujeta a Reportar, cuyos titulares sean una o varias Personas Específicas de EE.UU. o una Entidad que no es de EE.UU. con una o varias Personas que ejercen Control que sean una Persona Específica de EE.UU. No obstante lo anterior, una cuenta no será considerada como una Cuenta Reportable a EE.UU si la misma no está identificada como tal después de la aplicación del procedimiento de debida diligencia establecido en el Anexo I. ${ }^{49}$

Conforme a lo anterior, observamos que el IGA México-EUA establece diferentes definiciones de lo que significa una "cuenta reportable" para México y para los EUA, situación que rompe con la teoría de reciproci-

49 Secretaría de Hacienda y Crédito Público, "Anexo 23, 25, 25-Bis y 27 de la Resolución Miscelánea Fiscal para 2020, publicada el 28 de diciembre de 2019”, DOF, 17 de enero de 2020, véase Anexo 25, p. 5, disponible en: https://www.sat.gob.mx/normatividad/21127/ resolucion-miscelanea-fiscal-(rmf)- (fecha de consulta: 21 de agosto de 2020). 
dad que debe existir en los tratados internacionales conforme al derecho público internacional. Se debe resaltar que el Ejecutivo estadounidense declaró su apoyo por un alto grado de reciprocidad en el intercambio de información en torno a la FATCA, pero aseveró no poder asegurarlo. ${ }^{50}$ En efecto, un legislador opositor a la ley FATCA enfatizó que la obligación paralela de intercambio de información no era parte de la legislación habilitante de la FATCA ${ }^{51}$ (los IGAs celebrados por la Secretaría del Tesoro de los EUA).

Para el caso de México, el intercambio de información automático de cuentas financieras de los EUA está truncado, ya que, en primera instancia, no se reporta la información de cuentas bancarias de residentes fiscales mexicanos que existen en instituciones financieras americanas si estás no generan más de 10 dólares americanos al año, y en segunda, en el caso de cuentas bancarias de personas morales o arreglos, sólo se le reportan a México si dichas personas morales o arreglos son entes mexicanos, dejando de lado si el beneficiario efectivo de dichas cuentas es un residente para efectos fiscales en México. Es decir, un residente fiscal mexicano no será reportado al Servicio de Administración Tributaria (SAT) si constituye un Trust, o fideicomiso americano, y pone la cuenta bancaria a nombre de éste aunque por debajo del arreglo se encuentre la persona física que es residente para efectos fiscales de México.

Por otro lado, para los EUA la definición de "cuenta reportable" es mucho más amplia, ya que se obtiene mucha más información de México, puesto que se reportan todas las cuentas a nombre de titulares personas físicas o morales que sean residentes fiscales de los EUA, y en el caso de entidades que no sean americanas, existe la obligación de que se reporte la información de las personas físicas que sean las beneficiarias efectivas o que ejercen el control de dichas entidades y son residentes fiscales de los EUA.

50 Kudrle, Robert T., "Tax Havens and the Transparency Wave of International Tax Legalizaton”, University of Pennsylvania Journal of International Law, Estados Unidos, vol. 37, núm. 1153, 2016, p. 1176. El gobierno estadounidense señaló que ve con buenos ojos el intercambio de información recíproco, sin embargo, no se comprometió a asegurarlo.

51 Posey, Bill, "Carta de Bill Posey, miembro del Congreso estadounidense, a Jack Lew, secretario del Tesoro (15 de enero de 2014)”, Estados Unidos, 2014, disponible en: http: // www.repealfatca.com/downloads/Posey_letter_to_Sec._Lew_July_1,_2013.pdf. El legislador discutía sus preocupaciones sobre FATCA, en especial la obligación de los EUA de compartir información financiera de cuentas bancarias aperturadas en bancos estadounidenses. 
La situación descrita en los párrafos previos nos hace ver que hay un full disclosure de parte de México a los EUA, y un partial disclosure de parte de EUA a México.

Resulta importante señalar que la definición que ha adoptado México de "cuenta reportable" en el IGA México-EUA coincide con la definición contenida en el CRS de la OCDE o Estándar para el Intercambio Automático de Información sobre Cuentas Financieras en Materia Fiscal a que se refiere la recomendación adoptada por el Consejo de la OCDE el 15 de julio de 2014, del cual México forma parte y puede verse en el Anexo 25-Bis de la Resolución Miscelánea Fiscal para 2020. Dicha definición requiere un reporte multinivel en relación con el control de las cuentas financieras, como se observa a continuación:

D. Cuenta Reportable

1. El término “Cuenta Reportable” significa una cuenta mantenida por una o más Personas Reportables o por una ENF (Entidad No Financiera) Pasiva con una o más Personas que ejercen Control que sean Personas Reportables, siempre que haya sido identificada como tal de conformidad con los procedimientos de debida diligencia descritos en las Secciones II a VII. ${ }^{52}$

En virtud de que los EUA no han adoptado el Estándar Internacional del Intercambio Automático de Información de la OCDE, que es el consenso internacional adoptado por la mayoría de los países alrededor del mundo, y debido a que no comparte información de manera recíproca con México al no dar información de manera multinivel y sólo a un nivel, se puede determinar que los EUA pueden ser considerados como un paraíso fiscal, ya que ha adoptado leyes y políticas que imposibilitan el intercambio de información efectivo de información, y no obstante que debido a sus normas de KYC (Know Your Customer), o debida diligencia que llevan a cabo sus bancos e instituciones financieras, sus autoridades tributarias cuentan con la información relevante que resulta crucial para que otras jurisdicciones combatan la evasión fiscal de sus contribuyentes que utilizan como refugio a los EUA para evitar el pago de sus impuestos conforme a la legislación doméstica de otros países.

52 Secretaría de Hacienda y Crédito Público, “Anexos 23, 25, 25-Bis y 27...”, cit., véase Anexo 25-BIS, p. 20. 
Incluso se debe mencionar que las cortes estadounidenses sostienen un principio denominado el "revenue rule" o "regla de ingresos", que es un criterio del siglo XVIII derivado del Common Law que evita que los EUA reconozcan y ejecuten resoluciones foráneas. No reconoce las resoluciones foráneas en materia tributaria que conllevan a que si un contribuyente extranjero esconde su dinero en los EUA y no paga sus impuestos en su jurisdicción de origen, el gobierno extranjero no tiene forma de solicitar que se ejecute un crédito fiscal en contra de los activos del contribuyente en los EUA. ${ }^{53}$

Resulta ridículo que las acciones tomadas por los EUA, que supuestamente buscaban mayor transparencia e intercambio de información a nivel global y que dieron lugar al famoso caso UBS de 2009, hayan hecho que la mayoría de las inversiones que buscaban la secrecía bancaria se pasaran de Suiza a los EUA, ${ }^{54}$ que hoy por hoy no sólo resulta un refugio con la mayor estabilidad del mundo, sino que inclusive contiene factores que lo pueden clasificar como paraíso fiscal por su falta de intercambio de información hacia las demás jurisdicciones del mundo.

\section{CONCLUSIÓN}

Con la reforma fiscal de los EUA que entró en vigor en 2018, la tasa corporativa del ISR disminuyó a una del 21\%. La disminución en la tasa corporativa tributaria trajo dinamismo y competitividad a la economía estadounidense; sin embargo, también trajo como efecto inverso el que en México, conforme a la legislación fiscal de nuestro país, se le clasifique como un

53 Brunson, Samuel D., "The U.S. as Tax Haven. Aiding Developing Countries by Revoking the Revenue Rule”, Columbia Journal of Tax Law, Estados Unidos, vol. 5, núm. 170, 2013-2014, p. 182. La regla de ingresos o revenue rule es una regla anacrónica de los EUA que protege que la riqueza, incluso mal habida, se mantenga en los EUA por la falta de reconocimiento de resoluciones de autoridades extranjeras.

54 Drucker, Jesse, “The World's Favorite New Tax Haven is the United States”, Bloomberg Businessweek, Estados Unidos, 27 de enero de 2016, p. 2. Debido a que los EUA no cumplen con estándares internacionales de transparencia fiscal, como la falta de reporteo de manera multinivel, varias compañías y personas físicas han visto a los EUA como un importante lugar para llevar sus inversiones, inclusive los han nombrado la "Nueva Suiza". 
REFIPRE, dado que la tasa aludida es menor a una del 22.5\%, que representa la barrera impuesta por la LISR vigente en los Estados Unidos Mexicanos, al ser el resultado de obtener una tasa igual o mayor al 75\% de la tasa corporativa mexicana de personas morales que, según el artículo 9o. de la LISR, es del 30\%.

Conforme al capítulo que regula los REFIPRES de la LISR, los contribuyentes mexicanos que, a través de sus inversiones o participaciones en entidades o figuras jurídicas extranjeras, obtengan ingresos, se encuentran obligados a reconocer dichos ingresos de manera anticipada bajo un régimen anti diferimiento, incluso cuando aún no se les hayan distribuido por ser un régimen de castigo a las inversiones o participaciones en jurisdicciones en donde existen tasas tributarias bajas o nulas. El régimen de castigo también se aplica a ingresos generados vía entidades o figuras jurídicas transparentes para efectos fiscales, con independencia de la tasa efectiva en las jurisdicciones en donde se localicen.

Debido a lo anterior, y aunado al hecho de que los contribuyentes con residencia fiscal en México están obligados a pagar el ISR sobre los ingresos que hayan generado a nivel global, también deben pagar los impuestos correspondientes por los ingresos que hayan obtenido bajo un REFIPRE, y deben cumplir con las obligaciones de reporte establecidas en la LISR mediante declaraciones informativas de los ingresos generados en jurisdicciones de baja o nula imposición en el ejercicio fiscal inmediato anterior.

A los contribuyentes mexicanos que tienen alguna relación con jurisdicciones de baja o nula imposición les resulta necesario determinar si los ingresos que hayan obtenido mediante entidades o figuras jurídicas extranjeras están sujetas a un REFIPRE, por lo que deben hacer un análisis transaccional tomando en consideración la utilidad o pérdida que hayan obtenido por todas las operaciones realizadas en un ejercicio fiscal, atendiendo al impuesto que, efectivamente, hayan causado y pagado en el extranjero, para así llegar a la conclusión de si dichos ingresos, en realidad, están sujetos o no a un REFIPRE. Para llegar a dicha conclusión resulta menester que el contribuyente determine dos situaciones: a) cuál es el monto del ISR que la entidad o figura jurídica extranjera pagó en la jurisdicción foránea relacionada al monto de la transacción que se le atribuye al contribuyente mexicano, y b) el contribuyente debe contrastar el impuesto pagado en el extranjero con la cantidad que pagaría en México por el ingreso percibido conforme a la legislación aplicable. 
Con la disminución de la tasa corporativa del ISR de los EUA se entiende que se está lidiando con un REFIPRE, por lo que, en teoría, se estaría hablando de que México podría implementar medidas defensivas en materia tributaria, como retenciones de hasta el 40\% sin deducción alguna de los pagos realizados a dicha jurisdicción (con los EUA se disminuirían a las tasas ordinarias previstas en la LISR aplicables a pagos a residentes en el extranjeros, que, en la mayoría de los supuestos delTítulo V de la LISR y dependiendo del tipo de ingreso, son del 25\% por la existencia de un acuerdo amplio de intercambio de información entre México y los EUA).

De conformidad con lo comentado en el presente estudio, se ha dicho que en los EUA existen tasas del impuesto sobre la renta a nivel federal y estatal, y en algunos casos hasta a nivel municipal, lo que nos lleva a entender que, a nivel federal, se paga una tasa del 21\%, y dependiendo del estado de EUA en que se realicen las actividades, se debe pagar un ISR estatal que oscila entre el $0 \%$ y el 6\%. Por ejemplo, en Nueva York hay una tasa del ISR estatal del 5.8\%, en el Distrito de Columbia hay una tasa estatal del $8.25 \%$ y en Maryland también hay una del 8.25\%. Al sumar las tasas comentadas en los casos anteriores, en Nueva York se daría una tasa combinada federal y estatal del $26.8 \%$, en el Distrito de Columbia del $29.25 \%$ y en Maryland del 29.25\%. En contraste, Texas no tiene un IRS a nivel estatal, por lo que, al sumar las tasas federal, del 21\%, y estatal, del 0\%, se llegaría a una del 21\%.

Otro aspecto que no muchos estudios sobre el tema abordan son los impuestos sobre la renta a nivel municipal que se deben tomar en consideración con los ingresos gravables. Por decir, en Nueva York hay un ISR del $1.49 \%$ y en Maryland hay un ISR municipal del 2.28\%. Al sumar las tasas a nivel federal, estatal y municipal de los estados comentados anteriormente, vemos que las tasas acumuladas en Nueva York llegan al 28.29\% y en Maryland al 31.53\%. En contraste, ni en el Distrito de Columbia ni en Texas existen impuestos sobre la renta a nivel municipal, por lo que sus tasas acumuladas a nivel federal, estatal y municipal llegarían al $29.25 \%$ en el Distrito de Columbia y al $21 \%$ en Texas.

Conforme a lo comentado, para superar la barrera del 22.5\% prevista en la LISR en relación con los REFIPRES, vemos que en algunos casos se está en presencia de REFIPRES y en otros no. Por ejemplo, resulta notorio que si una empresa mexicana controla a una empresa en Texas, se encontraría en presencia de ingresos sujetos a un REFIPRE, dado que la tasa aplicable 
a dichos ingresos es del 21\%, mientras que si la empresa mexicana controla a una empresa en Nueva York, no se estaría en presencia de ingresos provenientes de un REFIPRE, ya que los ingresos estarían sujetos a un tasa combinada del 28.29\%.

En el caso mencionado de la empresa mexicana que controla a una empresa en Texas, veríamos que, conforme a la legislación anti diferimiento mexicana que evita que se mantengan ganancias afuera de México para evitar el pago del ISR, los ingresos de la empresa de Texas serían gravables para la empresa mexicana en el ejercicio en el que se generen y en la proporción de su participación, aun y cuando la empresa de Texas no haya distribuido dividendos hacia su matriz mexicana. Dichos ingresos deberán ser reportados ante las autoridades tributarias de México conforme a la legislación aplicable.

Sobre la legislación en vigor anterior a la reforma fiscal 2020, resulta claro que el acercamiento al problema de la suma de tasas de los impuestos sobre la renta a nivel federal, local y estatal no podría ser tomado en cuenta, ya que, jurídicamente y conforme al artículo 5o. del Código Fiscal de la Federación, las disposiciones fiscales son de aplicación estricta, porque ni el artículo 176 de la LISR ni el artículo 2o., párrafo 3, del Tratado para Evitar la Doble Tributación celebrado entre México y los Estados Unidos, consideraban a los impuestos sobre la renta distintos al ISR a nivel federal. Esto se corrobora claramente al observar que el párrafo 3 del artículo 2o. del Tratado para Evitar la Doble Tributación, claramente señala que el único impuesto comprendido por parte de los EUA es el ISR federal contemplado en su Código de Rentas Internas.

En opinión del autor, la postura sostenida por algunos comentaristas sobre el tema en relación con que el Tratado para Evitar la Doble Tributación le abría la puerta a los impuestos estatales y municipales de cada estado de EUA mediante el artículo 25 de dicho instrumento legal, no parece muy sólida, ya que sólo se refiere a una protección para que un estado no imponga impuestos a otro nivel gubernamental con el fin de afectar a los residentes fiscales de otro estado. Esto porque, evidentemente, el artículo 2o. señala que el tratado aplica nada más al ISR federal previsto en Código de Rentas Internas de los EUA y al ISR previsto en la LISR de México.

La anterior opinión legal se da pese a que el SAT, por presiones políticas y sin ningún fundamento legal sólido, señaló, en agosto de 2018 en una publicación de preguntas frecuentes del Portal del Servicio de Administración Tribu- 
taria, que el Capítulo I del Título VI de la LISR no distingue entre impuestos sobre la renta federales o locales, por lo que permitió como una facilidad administrativa - que no venía prevista en la Resolución Miscelánea Fiscal para 2018 - que se podían tomar en cuenta todos los impuestos sobre la renta efectivamente pagados sin importar a qué autoridad se les haya pagado. Además, en dicho comunicado el SAT no hizo un pronunciamiento claro sobre si los EUA eran un REFIPRE al decir, erróneamente, que la LISR no establece una lista de países o jurisdicciones que sean REFIPRES porque se le olvidó que, para efectos del artículo 178 de la LISR, se hace referencia al artículo 9o., fracción XLII, de las disposiciones transitorias de 2014, que imponen la obligación a contribuyentes de presentar una declaración informativa en el mes de febrero de cada año sobre los ingresos que hayan generado o generen en el ejercicio inmediato anterior sujetos a REFIPRES, o en sociedades o entidades cuyos ingresos estén sujetos a dichos regímenes. El anterior error se dio porque el SAT limitó su explicación a la fórmula matemática prevista en el artículo 176 de la LISR, que habla de la existencia de REFIPRES cuando los ingresos de mérito causen un impuesto inferior al 75\% del ISR que se causaría y pagaría en México y que, en el caso de personas morales, es del 30\%.

Por otro lado, conforme a la legislación en vigor a partir de la reforma fiscal 2020, no obstante las reglas de la LISR sobre REFIPRES, las adiciones parece que fueron específicamente diseñadas para atender la posibilidad de que exista un REFIPRE en los EUA; si permiten estimar el monto del ISR pagado por una entidad o figura jurídica en los EUA sin distinguir si el ISR a tomarse en consideración debe ser a nivel federal, estatal o municipal. Es decir, las adiciones al artículo 176 de la LISR abren la puerta para que se puedan adicionar las diferentes tasas del ISR que se causen en los EUA, sean éstas a nivel federal, estatal o municipal, para dar una tasa combinada que pueda superar la barrera de una igual o superior al 22.5\% que evite que los ingresos de dicha entidad sean considerados ingresos obtenidos por conducto de un REFIPRE.

Resulta importante señalar que aunque las adiciones al artículo 176 de la LISR permiten la adición de tasas a nivel federal, local y municipal, en algunos casos, como el de Texas y Wyoming, claramente se estaría en presencia de ingresos sujetos a REFIPRES en el supuesto de que una entidad mexicana controle a una entidad o figura jurídica que realice operaciones en esos estados.

Conforme a lo comentado, y aplicando la legislación fiscal vigente en 2020, se puede declarar que la comparación del ISR efectivamente causado 
y pagado en los EUA con el ISR que se causaría y pagaría en México debe hacerse tomando en consideración a los impuestos a nivel federal, estatal y municipal que la entidad o figura jurídica pagó en los EUA por sus transacciones, siempre y cuando los impuestos a nivel estatal y municipal sean ISR.

Pese a lo anterior, no se debe perder de vista que el párrafo octavo del artículo 176 de la LISR permite un comparativo de las tasas estatutarias de los impuestos sobre la renta foráneos con la tasa del 30\% prevista en el artículo 9o. de la LISR, pero sólo si la entidad extranjera no está sujeta a algún crédito o beneficio fiscal en su país o jurisdicción de residencia que reduzca su base imponible o impuesto a pagar que no se otorgaría en México, y cuando dicho país o jurisdicción tenga un acuerdo amplio de intercambio de información con México.

En relación con lo anterior, es necesario recordar que, como se comentó en el presente análisis, la Sección 164(a) del Código de Rentas Internas de los EUA establece que se permite deducir los impuestos sobre la renta estatales y locales como un gasto estrictamente indispensable del ISR federal, ${ }^{55}$ por lo que, en realidad, los impuestos sobre la renta estatales y locales pueden ser neutralizados para que sólo se pague el ISR a nivel federal del 21\%.

En resumen, al hacer un análisis conforme al artículo 176 de la LISR se puede arribar a la conclusión de que los EUA son un REFIPRE porque su tasa corporativa es del $21 \%$, la cual es menor a la tasa del $22.5 \%$ que se pone como límite para que la LISR no determine que una jurisdicción con una tasa inferior a la señalada es, en efecto, un REFIPRE.

Por otro lado, es importante enfatizar que los EUA no cumplen con el nuevo estándar de intercambio automático de información establecido en el CRS de la OCDE, pues ni siquiera participa en dicho instrumento aunque justifica su ausencia al señalar que tiene en vigor IGAs para mejorar el cumplimiento fiscal internacional, incluyendo la FATCA. Y como hemos visto, el intercambio automático de información entre los EUA y otras jurisdicciones, con relación a cuentas financieras, no es equitativo, ya que sólo reparte información a un nivel, mientras recibe información de manera multinivel. Aunado a esto, los EUA aún no han ratificado la Convención de Asistencia Administrativa Mutua en Asuntos Fiscales desarrollada por la

55 Murray, Jean, "What Business Tax Costs can be Deducted”, The Balance Small Business, Estados Unidos, 26 de agosto de 2019, disponible en: https: / /www.thebalancesmb.com/whatbusiness-tax-costs-can-be-deducted-398968 (fecha de consulta: 31 de agosto de 2020). 
OCDE, siendo que 128 jurisdicciones, dentro de las cuales está México y los países de Europa Occidental, ya lo han hecho.

Sumado a lo anterior, en 2018 la Tax Justice Network clasificó a los EUA, solamente detrás de Suiza, como el segundo paraíso fiscal más importante del mundo, de acuerdo con el Índice de Secreto Financiero 2018 de dicha institución. Situación que fue claramente reconocida por el Centro de Estudios Sociales y de Opinión Pública de la Cámara de Diputados de México en un estudio publicado el 7 de febrero de 2018.

Dado que los EUA no cumplen con sus obligaciones de intercambio de información con otras jurisdicciones, aunque en muchos casos sí cuenta con la información financiera requerida por autoridades tributarias foráneas, se podría determinar que los EUA son un REFIPRE por, precisamente, no cumplir con esas obligaciones de intercambio de información conforme a los criterios establecidos por la OCDE, en especial por lo sustentado por esta organización internacional en su Reporte Final de la Acción 5 del Proyecto BEPS.

Finalmente, y concluyendo, se puede afirmar que para efectos fiscales de México, los EUA sí califican como un REFIPRE conforme a lo previsto en la LISR, pues dicha jurisdicción tributa a una tasa baja a nivel corporativo conforme a los criterios mexicanos, que es menor al 75\% de la tasa corporativa del 30\% vigente en México. Pero, además, porque cumplen con uno de los factores determinantes para calificar a una jurisdicción como un REFIPRE — anteriormente llamado paraíso fiscal—, que es, como se dijo líneas antes, no cumplir con sus obligaciones de intercambio de información, según lo reglamentado por la OCDE.

\section{BibLIOGRAFÍA}

Álvarez Alcalá, Alil, Lecciones de derecho fiscal, 2a. ed., México, Oxford, 2015.

AuerbaCH, Alan J., "Measuring the Effects of Corporate Tax Cuts", Journal of Economic Perspectives, Estados Unidos, vol. 32, núm. 4, otoño de 2018. Avi-Yonah, Reuven S., Double Tax Treaties: An Introduction, Estados Unidos, University of Michigan Law School, SSRN, 2007. 
Esta revista forma parte del acervo de la Biblioteca Jurídica Virtual del Instituto de Investigaciones Jurídicas de la UNAM

Avi-Yonah, Reuven S. y VallesPinos, Martin, "The Elephant Always Forgets: US Tax Reform and the WTO”, University of Michigan Law \& Econ Research Paper, núm. 18-006; University of Michigan Public Law Research Paper, Estados Unidos, núm. 596, 28 de enero de 2018.

Banco Santander, S. A., "Cifras del comercio exterior en México", disponible en: https: / /es.portal.santandertrade.com/analizar-mercados/mexico /cifras-comercio-exterior.

BARRO, Robert J. y Furman, Jason, "Macroeconomic Effects of the 2017 Tax Reform", Brookings Papers on Economic Activity, Estados Unidos, vol. 2018, núm. 1, 2018.

BOLAÑos, Martha P., “Off Shore, los paraísos fiscales ¿para la evasión?”, Alto Nivel, 10 de abril de 2013, disponible en: https: / /www.ccpm.org.mx/avi sos/off_shore.pdf.

BRunson, Samuel D., "The U.S. as Tax Haven. Aiding Developing Countries by Revoking the Revenue Rule”, Columbia Journal of Tax Law, Estados Unidos, vol. 5, núm. 170, 2013-2014.

Calvo Nicolau, Enrique, Tratado del impuesto sobre la renta, México, Themis, 1998.

Cámara de Diputados del H. Congreso de la Unión, Gaceta Parlamentaria, año XXII, núm. 5398, 30 de octubre de 2019, disponible en: http://gaceta.diputados.gob.mx/Gaceta/64/2019/oct/20191030.html.

Cámara de Diputados del H. Congreso de la Unión, Ley del Impuesto Sobre la Renta, última reforma, Diario Oficial de la Federación (DOF), 9 de diciembre de 2019, disponible en: http: / /www.diputados.gob.mx/Leyes Biblio/pdf/LISR_301116.pdf.

Cockfield, Arthur J., "Big Data and Tax Haven Secrecy”, Florida Tax Review, Estados Unidos, vol. 18, 2016.

Colegio de Contadores Públicos de México e Instituto MeXicano DE CONTAdores Públicos, Introducción a los impuestos internacionales, México, IMCP, 2006.

Donohoe, Michael P. et al., "Back to the Drawing Board: The Structural and Accounting Consequences of a Switch to a Territorial Tax System”, National Tax Journal, Estados Unidos, vol. 66, núm. 3, 2014.

DrUCKER, Jesse, “The World's Favorite New Tax Haven is the United States”, Bloomberg Businessweek, Estados Unidos, 27 de enero de 2016.

GLOBAL FORUM ON TRANSPARENCY AND EXCHANGE OF INFORMATION FOR TAX MatTers, OECD, “Automatic Exchange of Information (AEOI): 
Status of Commitments", agosto de 2020, disponible en: https://Www. oecd.org/tax / automatic-exchange/ commitment-and-monitoring-process / AE OI-commitments.pdf.

GutiérreZ, Mario Alberto y ChÁveZ, Juan José, "Reforma Fiscal de los Estados Unidos y sus Efectos en México”, Cámara Española de Comercio y PwC, febrero de 2018, disponible en: https://camescom.com.mx/ wp-content/uploads/2018/02/Reforma-Fiscal-USA-27-feb-2018_.pdf.

Hakelber, Lukas, “The Power Politics of International Tax Cooperation: Luxembourg, Austria and the Automatic Exchange of Information", Journal of European Public Policy, Reino Unido, vol. 22, núm. 3, 2015.

HeInEmAnN, Friedrich et al., "Implications of the US Tax Reform for Transatlantic FDI", Intereconomics, Alemania, vol. 53, 2018.

HERZFELD, Mindy, “US Tax Reform: Worth Waiting 30 Years For?”, láminas de presentación, Estados Unidos, University of Florida College of Law, 30 de mayo de 2018.

Internal Revenue Service, "With new SALT limit, IRS Explains Tax Treatment of State and Local Tax Refunds", IR-2019-59, 29 de marzo de 2018, disponible en: https://www.irs.gov/newsroom/with-new-salt-limit-irs -explains-tax-treatment-of-state-and-local-tax-refunds.

KNYAZEV, Timur, US Tax Reform for Hipsters, Estados Unidos, Timur Knyazev, CPA, 2018.

KUDRLE, Robert T., "Tax Havens and the Transparency Wave of International Tax Legalizaton”, University of Pennsylvania Journal of International Law, Estados Unidos, vol. 37, núm. 1153, 2016.

Lyon, Andrew B. y MCBRIDE, William A., Assessing US Global Tax Competitiveness after Tax Reform, Estados Unidos, Pricewaterhouse Coopers LLP, National Tax Association, 9 de mayo de 2018.

MEINZER, Markus, "Automatic Exchange of Information as the New Global Standard: The End of (Offshore Tax Evasion) History", Tax Justice Network, Reino Unido, 27 de febrero de 2017.

Murray, Jean, "What Business Tax Costs can be Deducted", The Balance Small Business, Estados Unidos, 26 de agosto de 2019, disponible en: https: / / www.thebalancesmb.com/what-business-tax-costs-can-be-deducted398968.

NeChyba, Thomas J., "Local Property and State Income Taxes: The Role of Interjurisdictional Competition and Collusion”, Journal of Political Economy, Estados Unidos, vol. 105, núm. 2, abril de 1997. 
OCDE, "Combatir las prácticas fiscales perniciosas, teniendo en cuenta la transparencia y la sustancia, Acción 5-Informe final 2015”, 2015, disponible en: https://www.oecd-ilibrary.org/docserver/9789264241190-en.pdf? expires $=1598038726$ \&id $=$ id\&accname $=$ guest\&checksum $=5$ C89AF3 EB302C 7E25F17FBD4D2D61D74.

OCDE, "Harmful Tax Practices, an Emerging Global Issue", 1998, disponible en: https: / / www.oecd.org/tax/harmful/1904176.pdf.

Posey, Bill, "Carta de Bill Posey, miembro del Congreso estadounidense, a Jack Lew, secretario del Tesoro (15 de enero de 2014)”, Estados Unidos, 2014, disponible en: http://www.repealfatca.com/downloads/Posey_letter_ to_Sec._Lew_July_1,_2013.pdf.

"Regímenes fiscales preferentes y los Estados Unidos", Contaduría Pública, mayo de 2018, disponible en: http://contaduriapublica.org. $m x / 2018$ /05/03 / regimenes-fiscales-preferentes-y-los-estados-unidos /.

Rodríguez MEDINA, Gilberto, Comentarios sobre la disminución de la tasa del ISR corporativo de la reforma fiscal en Estados Unidos, México, Colegio de Contadores Públicos de México, 2018, PAF 701.

Secretaría de ECONOmÍa, Subsecretaría de Comercio ExTERIOR, GOBIERNO DE LOS ESTADOS UnIDOS MEXICANOS, "Exportaciones totales de México", disponible en: https: / / www.gob. $\mathrm{mx} / \mathrm{cms} /$ uploads / attachment / file/428436/Acum-Exporta nov2018.pdf.

SeCretaría de Hacienda y CRÉdito Público, “Anexo 23, 25, 25-Bis y 27 de la Resolución Miscelánea Fiscal para 2020, publicada el 28 de diciembre de 2019", DOF, 17 de enero de 2020, disponible en: https: / / www.sat. gob. $\mathrm{mx} /$ normatividad/21127/resolucion-miscelanea-fiscal-(rmf)-.

Wagner, Alexander F. et al., "Unequal Rewards to Firms: Stock Market Responses to the Trump Election and the 2017 Corporate Tax Reform", AEA Papers and Proceedings, Estados Unidos, 108: 590-96, 2018.

WalCZAK, Jared, 2020 State Business Tax Climate, Tax Foundation, disponible en: https: / / taxfoundation.org/2020-state-business-tax-climate-index /.

WANG, Emily, "The Opaque Future of Tax Information Sharing between the United States and China: An Analysis of Bank Secrecy Laws and the Likelihood of Entrance into a Tax Information Exchange Agreement", Hastings International \& Comparative Law Review, Estados Unidos, vol. 35, núm. 411, 2012. 